\title{
FORMAÇÃO DOCENTE NO ENSINO SUPERIOR DE QUÍMICA: CONTRIBUIÇÕES DOS PROGRAMAS DE APERFEIÇOAMENTO DE ENSINO
}

\author{
Daniel Lino Teodoro, Josias Falararo Pagotto, Artur de Jesus Motheo e Salete Linhares Queiroz* \\ Instituto de Química de São Carlos, Universidade de São Paulo, CP 780, 13560-970 São Carlos - SP, Brasil
}

Recebido em 8/6/10; aceito em 28/10/10; publicado na web em 9/2/11

\begin{abstract}
TEACHER EDUCATION IN UNDERGRADUATE CHEMISTRY TEACHING: CONTRIBUTIONS OF TEACHING IMPROVEMENT PROGRAMS. The literature on the challenges of teacher education in undergraduate chemistry teaching is limited. In the present study, the application of didactic proposals elaborated by two authors of this paper, graduate students and teaching assistants of the teaching improvement program at University of São Paulo, was investigated in terms of their contribution to the teaching assistants' education and undergraduate students' receptivity toward them. Such proposals were based on the jigsaw cooperative learning strategy and applied in two undergraduate courses. The results indicate students' good receptivity and suggest their importance to teaching assistants' education.
\end{abstract}

Keywords: teacher education; higher education; Chemistry.

\section{INTRODUÇÃO}

A Lei Federal 9394, de 20 de dezembro de 1996, que estabelece as Diretrizes e Bases da Educação Nacional, afirma que os programas de pós-graduação devem ser vistos como lócus de preparação pedagógica para o exercício da atividade docente. ${ }^{1}$ Nesse contexto, diversas iniciativas vêm sendo tomadas com o intuito de garantir uma adequada preparação pedagógica para os futuros docentes do ensino superior, dentre as quais destacamos aquela que instituiu o estágio docente como parte integrante da formação dos pós-graduandos, bolsistas da Coordenação de Aperfeiçoamento de Pessoal de Nível Superior (CAPES). ${ }^{2}$

Buscando satisfazer as exigências da CAPES, ações voltadas ao desenvolvimento dos estágios de docência e à criação de disciplinas de caráter pedagógico se iniciaram ou se intensificaram em Instituições de Ensino Superior (IES). No entanto, na área de Química, são ainda escassas as investigações reportadas na literatura destinadas a discutir os desafios e as possibilidades da formação docente nesse nível de ensino. Dentre os trabalhos que abordam essa temática, destacam-se os de Arroio et al. ${ }^{3,4} \mathrm{e}$ o de Zanon et al.. ${ }^{5}$ Em um dos trabalhos, Arroio et al. ${ }^{3}$ investigam as concepções sobre a formação de professores de um grupo de alunos do Programa de Pós-Graduação em Físico-Química, do Instituto de Química de São Carlos, Universidade de São Paulo (IQSC/USP). No segundo, analisam a experiência de um grupo de alunos do mesmo Programa na realização de cursos de extensão relacionados à química computacional. ${ }^{4}$ Zanon et $a l .{ }^{5}$ analisam as visões de alunos de pós-graduação de uma universidade estadual paulista sobre as necessidades formativas de professores de química do ensino superior.

Neste trabalho tivemos como objetivo relatar a aplicação e avaliação de duas propostas didáticas de caráter cooperativo elaboradas pelos dois primeiros autores do presente manuscrito, enquanto pós-graduandos e estagiários do Programa de Aperfeiçoamento de Ensino (PAE) da USP, e tecer considerações sobre as contribuições do Programa para a formação dos pós-graduandos.
O PAE foi regulamentado pela Portaria GR 3588, de maio de 2005, e tem como objetivo aprimorar a formação do pós-graduando para atividade didática de graduação. O PAE, de caráter obrigatório para os bolsistas CAPES e optativo para os demais alunos da pós-graduação, é composto de duas etapas. Na primeira, ocorre a preparação pedagógica, usualmente relacionada a uma disciplina de pós-graduação com conteúdos voltados para as questões do ensino superior ou a um conjunto de conferências. Na segunda etapa o pós-graduando realiza o estágio supervisionado, sendo assistido por um docente. Nesta etapa participa das atividades da disciplina e tem a possibilidade de sugerir e aplicar propostas didáticas que considere relevantes. ${ }^{6}$

As propostas relatadas neste trabalho, pautadas no método cooperativo jigsaw, ${ }^{7,8}$ foram elaboradas na segunda etapa do Programa e aplicadas nas disciplinas Comunicação e Expressão em Linguagem Científica I e Laboratório de Química Geral. A primeira é oferecida aos ingressantes do curso de Bacharelado em Química do IQSC/ USP e a segunda, aos alunos do segundo semestre do curso de Bacharelado em Ciências Físicas e Biomoleculares do Instituto de Física de São Carlos/USP.

Os referenciais teóricos que subsidiaram a elaboração da proposta (pautados no trabalho de Johnson et al. ${ }^{7}$ sobre métodos cooperativos de aprendizagem) e a tessitura das considerações sobre as contribuições do Programa para a formação dos pósgraduandos (pautados no trabalho de Carvalho e Gil-Pérez ${ }^{9}$ sobre necessidades formativas dos professores de ciências) são sucintamente descritos a seguir.

Cabe ainda destacar que Programas de natureza semelhante à do PAE estão presentes em outras IES (Programa de Estágio Supervisionado de Capacitação Docente (PESCD), ${ }^{10}$ da Universidade Federal de São Carlos; Programa de Estágio Docente (PED), ${ }^{11}$ da Universidade Estadual de Campinas etc.), evidenciando a crescente atenção que vem sendo dispensada ao preparo de alunos de pós-graduação para o exercício da profissão docente no ensino superior, assim como a necessidade de realização de pesquisas que tratem do assunto. 


\section{REFERENCIAIS TEÓRICOS}

\section{Métodos cooperativos de aprendizagem}

A aprendizagem cooperativa se distingue pela sua natureza social, na qual se desenvolvem habilidades intelectuais e sociais, com o estabelecimento de inter-relações sociais. Nela, os estudantes interagem e compartilham suas ideias melhorando sua compreensão individual e mútua. ${ }^{7,8}$

Seguindo as bases teóricas fornecidas por Johnson et al., ${ }^{7}$ para que o trabalho cooperativo seja funcional e produtivo, as seguintes condições precisam estar presentes no processo de ensino-aprendizagem: Interdependência positiva: o sentimento do trabalho conjunto para um objetivo comum em que cada um se preocupa com a aprendizagem dos colegas; Responsabilidade individual: cada elemento do grupo sente-se responsável pela sua própria aprendizagem e pela dos colegas e contribui ativamente para o grupo; Interação face-a-face: oportunidade de interagir com os colegas de modo a explicar, elaborar e relacionar conteúdos; Habilidades interpessoais: competências de comunicação, confiança, liderança, decisão e resolução de conflito; Processamento grupal: balanços regulares e sistemáticos do funcionamento do grupo.

Existem várias formas de organização das atividades de aprendizagem cooperativa, dentre as quais se destacam: jigsaw, instrução complexa; TGT (Teams-Games-Tournament); STAD (Student Teams Achievement Division). ${ }^{8}$ As principais características do método jigsaw, empregado na proposta elaborada pelos estagiários, são apresentadas a seguir.

No método jigsaw o trabalho que cada aluno realiza é essencial para a concretização do trabalho final do grupo e a sua sistemática de funcionamento se assemelha a de um quebra-cabeça que somente está concluído quando todas as peças se encaixam. O método envolve alunos em pequenos grupos de estudo. O material acadêmico é dividido em pequenas partes e cada membro do grupo é designado a estudar apenas uma parte. Os alunos de grupos originais diferentes (grupos de base), que foram designados a estudar a mesma parte, estudam e discutem seus materiais juntos (grupos de especialistas). Depois da discussão, cada aluno retorna ao seu grupo de base e compartilha o aprendizado adquirido sobre sua parte com os outros membros. Assim, no final, todos os membros entram em contato com todo o conteúdo e o aprendizado dos alunos pode ser avaliado individualmente.,

\section{Necessidades formativas dos professores de Ciências}

A questão sobre o que priorizar na formação do professor foi alvo de estudos de Carvalho e Gil-Pérez, ${ }^{9}$ que apontaram como sendo as seguintes as necessidades formativas dos professores de ciências:

Conhecer o conteúdo da disciplina, isto é, conhecer os problemas que originaram a construção dos conhecimentos, as metodologias empregadas pelos cientistas, as interações Ciência/ Tecnologia/ Sociedade, alguns desenvolvimentos científicos recentes e saber selecionar os conteúdos adequados e adquirir novos conhecimentos.

Saber preparar atividades capazes de gerar uma aprendizagem efetiva (estratégias de ensino), ao propor, por exemplo, uma estratégia de ensino baseada em tratamento de situações problemáticas mediante um trabalho de pesquisa.

Questionar as ideias docentes de "senso comum" sobre o ensino e a aprendizagem de ciências, o que exige conhecer a existência de um pensamento espontâneo do que é "ensinar ciências" e analisá-lo criticamente, questionar o caráter "natural" do fracasso generalizado dos alunos nas disciplinas científicas.

Adquirir conhecimentos teóricos sobre aprendizagem de ciências, o que permite ao professor, por exemplo, reconhecer que as concepções alternativas são difíceis de serem substituídas por conhecimentos científicos, saber que os alunos aprendem significativamente construindo conhecimentos (respostas a questões problemáticas).

Saber analisar criticamente o "ensino tradicional", ou seja, conhecer as limitações dos currículos tradicionais, da introdução de conhecimentos, dos trabalhos práticos e exercícios propostos e das formas habituais de avaliação.

Saber dirigir os trabalhos dos alunos, isto é, apresentar e saber dirigir adequadamente as atividades, realizar sínteses e reformulações que valorizem as contribuições dos alunos, criar um bom clima de funcionamento da aula, fruto de um relacionamento entre professor e alunos marcados pela cordialidade e aceitação etc.

Saber avaliar e utilizar esse recurso como instrumento de aprendizagem que permita fornecer um feedback adequado para promover o avanço dos alunos, ampliar o conceito e a prática da avaliação ao conjunto de saberes que queira priorizar no aprendizado, introduzir formas de avaliação de sua própria tarefa docente.

Tendo em vista as considerações dos autores, estabeleceremos relações entre as necessidades formativas apontadas e as ações executadas pelos pós-graduandos durante o estágio PAE, que favoreceram o suprimento de tais necessidades.

\section{PERCURSO METODOLÓGICO}

O percurso metodológico seguido incluiu, inicialmente, a participação dos pós-graduandos nas duas etapas do PAE: na primeira, atuaram como alunos da disciplina SQF5798 - Aspectos Avançados da Docência no Ensino Superior de Química, obrigatória para todos os participantes do PAE do IQSC/USP; na segunda etapa elaboraram propostas didáticas que foram aplicadas nas disciplinas mencionadas anteriormente.

Concluída a segunda etapa, os estagiários elaboraram um questionário de avaliação das propostas, que foi aplicado junto aos alunos de ambas as disciplinas. Este se pautou no trabalho de Eilks, ${ }^{12}$ tendo em vista o conhecimento das impressões dos alunos sobre a aplicação do método cooperativo. Questões relacionadas à potencialidade do método estão presentes no questionário, composto de dez afirmações, elencadas a seguir:

Q1: Eu pude trabalhar com mais independência no formato de aula jigsaw do que faço normalmente nas aulas expositivas.

Q2: Eu trabalhei com mais intensidade no formato de aula jigsaw do que costumo trabalhar durante as aulas expositivas/expositivas dialogadas.

Q3: Eu não gostei de trabalhar no formato de aula jigsaw porque meu trabalho ficou muito dependente do desempenho dos meus colegas.

Q4: Eu gostei de trabalhar no formato de aula jigsaw porque pude trabalhar junto com outros colegas.

Q5: Eu gostaria de participar novamente de aulas no formato jigsaw na disciplina Comunicação e Expressão em Linguagem Científica I/Laboratório de Química Geral.

Q6: O uso de diferentes métodos de ensino (como o formato de aula jigsaw) torna nossas aulas mais divertidas e menos cansativas.

Q7: Eu acho que o formato de aula jigsaw é confuso e desestruturado.

Q8: Eu acredito que aprendi muito sobre o conteúdo "Algumas Formas de Divulgação Científica"/ "Ácidos e Bases" trabalhando no formato de aula jigsaw.

Q9: Eu prefiro quando o professor discute tópicos com a classe toda (aula expositiva dialogada) do que quando nós temos que trabalhar em pequenos grupos.

Q10: Eu teria gostado mais se o professor/estagiário PAE tivesse nos ajudado mais diretamente e corrigido o nosso trabalho após cada uma das etapas do jigsaw. 
A frequência das respostas, expressa em escala Likert de cinco pontos (Concordo Fortemente (CF), Concordo (C), Indeciso (I), Discordo (D), Discordo Fortemente (DF)), foi quantificada e analisada.

Por fim, com base nas etapas cumpridas pelos pós-graduandos e nas respostas oferecidas pelos graduandos ao questionário de avaliação das propostas, tecemos considerações sobre as contribuições do Programa para a formação dos estagiários, na perspectiva do suprimento das necessidades formativas dos professores de ciências dele decorrente.

\section{APLICAÇÃO DAS PROPOSTAS DIDÁTICAS}

Conforme mencionado anteriormente, o jigsaw foi aplicado nas disciplinas Comunicação e Expressão em Linguagem Científica I e Laboratório de Química Geral. A disciplina Comunicação e Expressão em Linguagem Científica I ( 2 créditos, teórica) visa a discussão das diversas formas como a ciência é divulgada, a apresentação aos estudantes de alguns tipos de documentos científicos e suas características peculiares, assim como de fontes de informação em ciência e tecnologia. A disciplina Laboratório de Química Geral (6 créditos, prática) visa o oferecimento ao aluno de um primeiro contato com o laboratório de química, com o ensino de técnicas básicas de laboratório, condutas de segurança, e busca favorecer o estabelecimento de relações entre os aspectos teóricos e práticos inerentes a cada experimento.

\section{Disciplina "Comunicação e Expressão em Linguagem Científica I"}

Antes do início da atividade cooperativa os alunos matriculados nesta disciplina no $1^{\circ}$ semestre de 2009 foram distribuídos em 12 grupos de base heterogêneos, como recomendado por Johnson et $a l^{7}$ (10 grupos formados por 5 alunos e 2 formados por 6 alunos). Estes foram formados tendo em vista a aplicação de um questionário de caracterização preenchido no primeiro dia de aula. A partir das respostas dos alunos, os seguintes critérios foram considerados na formação dos grupos: formação estudantil dos alunos, habilidade de escrita, interesse e motivação pela leitura.

$\mathrm{Na} 1^{\mathrm{a}}$ aula de realização da atividade o professor discutiu brevemente as diversas formas como a ciência é divulgada. Em seguida, solicitou que os membros dos grupos de base trouxessem, para a aula seguinte, os seguintes tipos de documentos científicos: artigo original de pesquisa; artigo de divulgação científica; artigo de revisão; artigo relacionado à educação em química; teses/dissertações. Tais documentos foram escolhidos por serem considerados representativos para o alcance dos objetivos propostos na disciplina.

$\mathrm{Na} 2^{\mathrm{a}}$ aula, os alunos se reuniram em seus grupos de base e solucionaram questões de caráter geral com relação às características dos cinco tipos de documentos investigados. $\mathrm{Na}^{\mathrm{a}}$ aula os alunos se reuniram nos grupos de especialistas e solucionaram questões específicas para um dos tipos de documentos; ou seja, se especializaram em um dos tipos de texto. Nessa perspectiva, aos grupos de especialistas foram dados nomes referentes aos documentos por eles estudados, por exemplo: grupo de especialistas em artigos originais de pesquisa, grupo de especialistas em artigos de divulgação científica.

$\mathrm{Na} 4^{\mathrm{a}}$ aula cada um dos grupos de especialistas apresentou oralmente a síntese dos conhecimentos adquiridos para a turma inteira e, em seguida, os alunos se reorganizaram, voltando aos seus grupos de base, nos quais refizeram as respostas dadas na $1^{\mathrm{a}}$ aula às questões de caráter geral. Estas foram refeitas com o intuito de aprofundá-las, uma vez que o grupo de base contava, no momento, com especialistas em cada um dos tipos de texto em estudo. Por fim, os alunos responderam ao questionário de avaliação da atividade, apresentado no tópico anterior.

\section{Disciplina “Laboratório de Química Geral”}

Antes do início da atividade cooperativa os alunos matriculados nesta disciplina no $1^{\circ}$ semestre de 2009 foram distribuídos em 5 grupos de base heterogêneos, cada um com 4 membros. Estes foram formados a partir dos resultados alcançados em uma prova (tópico ácidos e bases) aplicada antes do início da primeira atividade do jigsaw. Com base nas notas obtidas, cada um dos grupos ficou constituído por um aluno que obteve nota superior a 5,0; um aluno com nota entre 4,0 e 5,0; um aluno com nota superior a 3,0 e menor que 4,0; um aluno com nota menor que 3,0.

$\mathrm{Na}$ aula inicial de realização da atividade os alunos dos grupos de base discutiram questões simples sobre o tópico ácidos e bases e seguiram o procedimento experimental indicado na apostila usualmente empregada no Laboratório de Química Geral, relacionado ao mesmo assunto, que ocorreu em três etapas: na primeira, os alunos fizeram a padronização do ácido clorídrico por meio de uma titulação, utilizando carbonato de sódio como padrão primário. Como se trata de uma titulação colorimétrica foi utilizado alaranjado de metila como indicador ácido-base, próprio para a faixa de viragem desse sistema; na segunda, os alunos utilizaram soluções de ácido clorídrico com pHs entre 1 e 6 e testaram diferentes indicadores, com o propósito de observar a faixa de viragem e as cores apresentadas pelos indicadores em diferentes pHs. Desta maneira, verificaram qual indicador é mais indicado para diferentes faixas de viragem. $\mathrm{Na}$ terceira etapa, os alunos mediram o pH de um ácido fraco (foi utilizado ácido acético) por meio do uso do pHmetro e por meio de indicadores ácido-base, com o objetivo de observar a sensibilidade de um indicador ácido-base frente a uma medida mais precisa de $\mathrm{pH}$ (utilizando o pHmetro). Além do ácido acético, foi medido também o pH de uma solução tampão preparada a partir de ácido acético e acetato de sódio e feitos cálculos para determinar a constante ácida $\left(\mathrm{K}_{\mathrm{a}}\right)$ desse ácido fraco.

A atividade prática proporcionou o contato inicial dos alunos dos grupos de base com aspectos relacionados à diluição, estequiometria de reação ácido-base, funcionamento de indicador ácido-base etc. Tendo em vista o procedimento experimental realizado, o tópico ácidos e bases foi dividido em quatro subtópicos: teorias ácidobase, ácidos e bases fracos, escalas de pH e soluções tampão. Estes foram posteriormente estudados por 4 grupos de especialistas, com 5 componentes.

A constituição dos grupos de especialistas foi comunicada aos alunos na semana seguinte à realização da prática sobre ácidos e bases, quando cada um dos especialistas recebeu um guia de estudos, no qual estavam indicados: nome do grupo de especialistas (por exemplo, especialistas 1: teorias ácido-base); os objetivos a serem alcançados com a realização das tarefas propostas no guia (por exemplo, entender a definição de ácidos e bases, com base nas teorias de Arrhenius, Brönsted-Lowry, Lewis e Pearson, e saber classificar as espécies que compõem um equilíbrio em ácidos ou bases, de acordo com as teorias em questão); bibliografia (livros de Química Geral de nível universitário); tarefa consistindo de 10 questões dissertativas.

As atividades nos grupos de especialistas foram realizadas em horário extraclasse, tendo sido estipulado o prazo de 1 mês para a sua conclusão. Ao final desse período, os estudos realizados pelos grupos de especialistas foram avaliados por meio da aplicação de uma prova individual, dissertativa de 8 questões. Foram elaborados 4 tipos de provas diferentes, específicas para cada um dos subtópicos estudados. Estas provas foram aplicadas em horário extraclasse, tendo duração de $1 \mathrm{~h}$.

Antes da prova os grupos de especialistas se reuniram na sala por aproximadamente $40 \mathrm{~min}$, quando trocaram informações e sanaram algumas dúvidas entre si. Na ocasião, o estagiário PAE auxiliou os 
alunos nesse processo. Os resultados das provas dos especialistas foram satisfatórios, uma vez que apenas 2 alunos tiraram nota inferior a 5, sendo a média da turma de 7,3 $\pm 1,9$. Em termos dos diferentes grupos de especialistas, as notas médias com os respectivos desviospadrão foram: teorias ácido-base $=9,5 \pm 0,5$; ácidos e bases fracos $=6,2 \pm 2,0$; escalas de $\mathrm{pH}=7,0 \pm 1,7$; soluções tampão $=6,8 \pm 1,8$.

$\mathrm{Na}$ última etapa dos trabalhos, os alunos especialistas em um determinado tema retornaram à formação inicial dos grupos de base e, sob a coordenação do estagiário PAE, cada grupo de base realizou uma atividade que consistiu na resolução de 4 questões, sendo que cada uma se referia a um dos 4 subtópicos estudados pelos especialistas. Na ocasião, os alunos também responderam ao questionário de avaliação da proposta, mencionado anteriormente.

\section{RESULTADOS E DISCUSSÃO}

A análise dos questionários de avaliação das propostas didáticas, somada a algumas considerações sobre ações realizadas pelos estagiários nas etapas do PAE, permitiram o estabelecimento de relações entre as necessidades formativas apontadas por Carvalho e Gil-Pérez ${ }^{9}$ e o suprimento de tais necessidades em cada uma das etapas do estágio docente.

\section{Questionário de avaliação da proposta didática}

Para que a discussão a respeito da avaliação dos graduandos sobre a proposta pudesse ser feita de forma mais clara, inicialmente agrupamos as afirmações contidas no questionário em duas categorias, distribuídas nas Figuras 1 e 2. Apresentamos na Figura 1 as respostas dadas para as afirmações Q1 a Q5, que se relacionam à opinião dos alunos com relação à sua conduta durante a realização da estratégia e à sua satisfação com relação à atividade realizada. Nas afirmações Q1 e Q2 os alunos opinaram sobre a independência e intensidade com que conduziram as tarefas pertencentes à atividade realizada.

Os resultados foram positivos com relação a tais afirmações, principalmente na disciplina Comunicação e Expressão em Linguagem Científica I (Figura 1a), uma vez que grande parte dos alunos afirma ter trabalhado com maior independência $(76,37 \%$; somatório das respostas $\mathrm{CF}$ e C) e intensidade $(57,41 \%$; somatório das respostas $\mathrm{CF}$ e C) durante a realização da atividade. Para a disciplina Laboratório de Química Geral (Figura 1b), 57,90\% dos alunos responderam de forma positiva à afirmação Q1 (somatório das respostas $\mathrm{CF}$ e C), porém somente $31,58 \%$ responderam favoravelmente à afirmação Q2 (somatório das respostas $\mathrm{CF}$ e $\mathrm{C}$ ), sugerindo que, embora parte considerável dos alunos tenha trabalhado mais independentemente no formato de aula jigsaw, poucos deles consideraram ter trabalhado com mais intensidade do que no modelo de aulas expositivas/expositivas dialogadas. A diferença no percentual positivo de respostas à questão Q2 nas duas disciplinas pode estar relacionada ao fato das atividades dos especialistas terem ocorrido em horário extraclasse na disciplina Laboratório de Química Geral. Sem o acompanhamento direto do estagiário PAE, possivelmente a realização dos trabalhos por parte dos grupos ocorreu com menor intensidade.

Com relação às impressões dos alunos sobre a dependência do trabalho dos demais colegas para o sucesso da tarefa realizada (afirmações Q3 e Q4), é possível verificar que os resultados foram bastante favoráveis à proposta em ambas as disciplinas, uma vez que a discordância dos alunos em relação à afirmação Q3 foi elevada: $67,57 \%$ de discordância (somatório das respostas De DF) na disciplina Comunicação e Expressão em Linguagem Científica I (Figura 1a) e $78,94 \%$ de discordância (somatório das respostas D e DF) na disciplina Laboratório de Química Geral (Figura 1b). De forma complementar, a grande maioria dos alunos concordou haver gostado de trabalhar no

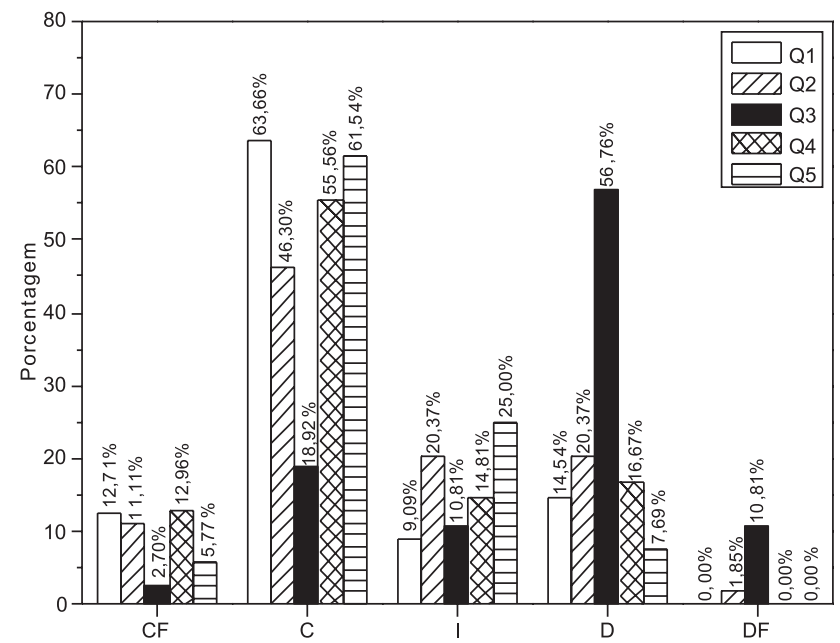

(a)

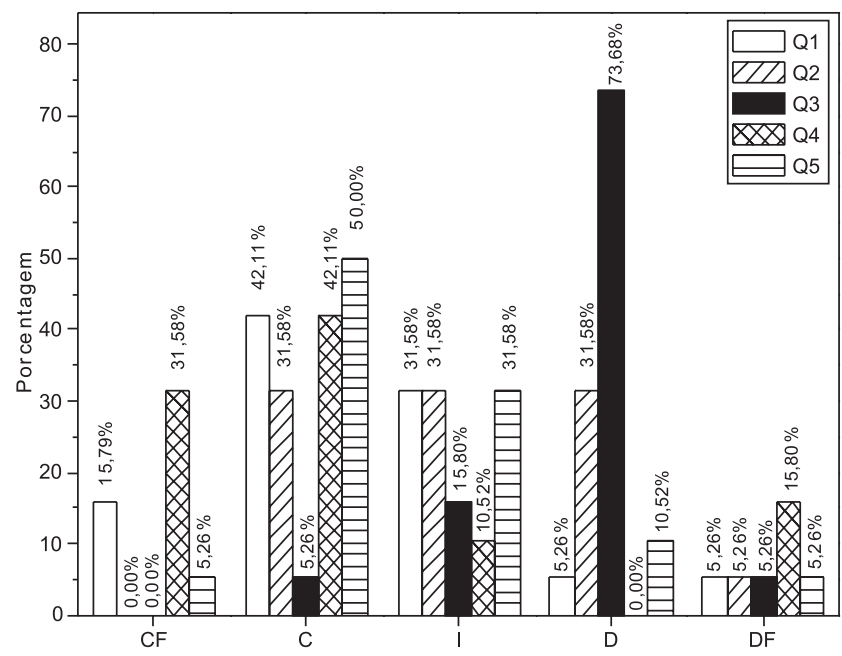

(b)

Figura 1. Índice de respostas em escala Likert de cinco pontos para as afirmações Q1 a Q5 do questionário de avaliação das propostas didáticas pelos alunos das disciplinas: (a) Comunicação e Expressão em Linguagem Científica I; (b) Laboratório de Química Geral. CF = concordo fortemente; $C=$ concordo $;=$ indeciso D = discordo fortemente D = discordo $D F=$ discordo fortemente

formato de aula jigsaw porque era possível trabalhar junto com os outros colegas (Q4): 68,52\% de concordância (somatório das respostas C e CF) na disciplina Comunicação e Expressão em Linguagem Científica I (Figura 1a) e 73,69\% de concordância (somatório das respostas C e CF) na disciplina Laboratório de Química Geral (Figura 1b).

A satisfação dos alunos frente às atividades realizadas foi considerável, uma vez que a concordância em relação à afirmação Q5, que se referia ao desejo de nova participação em aulas no formato jigsaw, superou a metade dos alunos em ambas as turmas: 67,31\% de concordância (somatório das respostas $\mathrm{C}$ e $\mathrm{CF}$ ) na disciplina Comunicação e Expressão em Linguagem Científica I (Figura 1a) e $55,26 \%$ de concordância (somatório das respostas C e CF) na disciplina Laboratório de Química Geral (Figura 1b).

Apresentamos na Figura 2 as respostas dadas para as afirmações, Q6 a Q10, que dizem respeito à opinião dos alunos sobre a realização das atividades no formato jigsaw (Q6 e Q7) e às suas contribuições para o aprendizado dos conteúdos estudados (Q8), assim como às suas percepções com relação à conduta do professor (Q9 e Q10). 


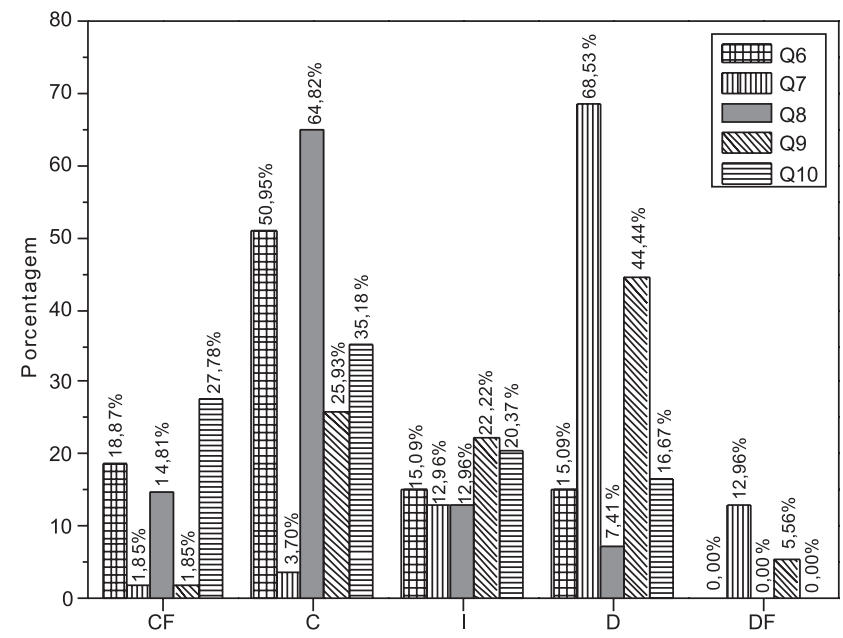

(a)

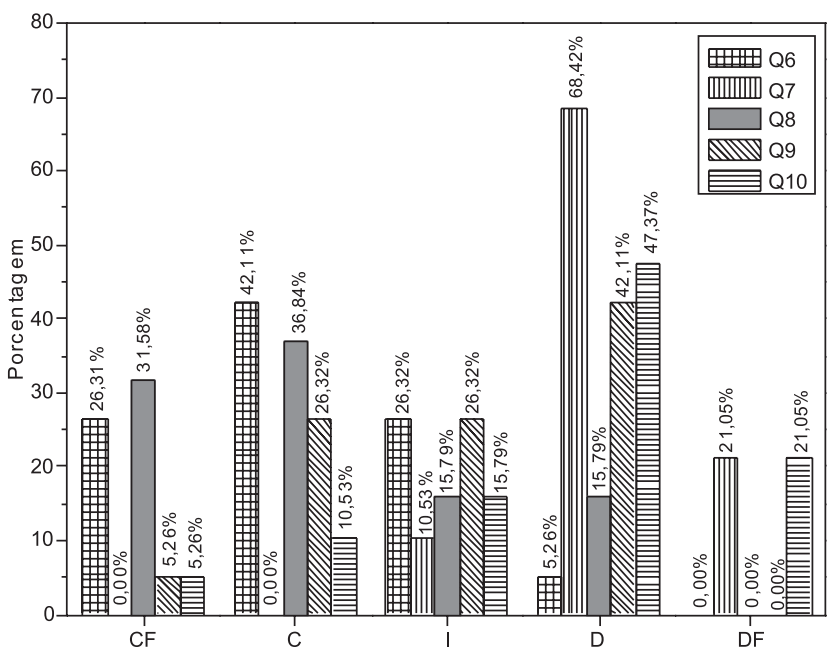

(b)

Figura 2. Índice de respostas em escala Likert de cinco pontos para as afirmações Q6 a Q10 do questionário de avaliação das propostas didáticas pelos alunos das disciplinas: (a) Comunicação e Expressão em Linguagem Científica I; (b) Laboratório de Química Geral. CF = concordo fortemente; $C=$ concordo $;=$ indeciso $;=$ discordo fortemente $D=$ discordo $; D F=$ discordo fortemente

As respostas dadas à Q6 mostram que 69,82\% dos alunos da disciplina Comunicação e Expressão em Linguagem Científica I (Figura 2a) e 68,42\% de Laboratório de Química Geral (Figura $2 b$ ) concordaram (somatório das respostas $\mathrm{C}$ e $\mathrm{CF}$ ) que métodos como o jigsaw tornam as aulas menos cansativas e mais divertidas. As respostas dadas a Q7, nas duas disciplinas, evidenciam que os alunos, em sua maioria, reconheceram a atividade como organizada, o que é relevante, já que um dos maiores obstáculos ao trabalho em grupo reside, justamente, na dificuldade da organização das tarefas. ${ }^{7,8}$ De fato, verificamos que $81,49 \%$ dos alunos da disciplina Comunicação e Expressão em Linguagem Científica I (Figura 2a) e 89,47\% de Laboratório de Química Geral (Figura 2b) discordaram (somatório das respostas D e DF) da afirmação que diz ser o formato de aula jigsaw confuso e desestruturado. Esse resultado positivo se deve, provavelmente, a dois fatores: a organização, imposta pela própria estrutura da atividade cooperativa, e à forma com que os docentes e os estagiários PAE a conduziram em ambas as disciplinas.
No que diz respeito ao favorecimento da compreensão de conceitos (Q8), a grande maioria dos alunos concordou com tal afirmação, tanto na disciplina de Comunicação e Expressão em Linguagem Científica I (79,63\%, somatório das respostas CF e C), quanto na disciplina de Laboratório de Química Geral $(68,42 \%$, somatório das respostas $\mathrm{CF}$ e C), conforme ilustra a Figura 2. Assim, a natureza cooperativa do formato jigsaw não prejudicou o aprendizado dos conteúdos ministrados nas disciplinas.

Duas afirmações se relacionavam à condução das aulas pelos professores: a primeira, de caráter geral (Q9), solicitava aos alunos que indicassem se preferiam o formato de aula expositiva dialogada ao formato de trabalho em pequenos grupos; a segunda, de caráter específico (Q10), solicitava aos alunos que indicassem se teriam gostado mais da atividade no formato adotado caso o professor/estagiário PAE os tivesse auxiliado mais diretamente no processo, corrigindo os trabalhos após cada uma das etapas do jigsaw. No que diz respeito à afirmação Q9, na disciplina de Comunicação e Expressão em Linguagem Científica I (Figura 2a), 27,78\% dos alunos explicitaram sua preferência por aulas expositivas dialogadas (somatório das respostas $\mathrm{CF}$ e $\mathrm{C}$ ) e $50 \%$ por aulas nas quais predominam atividades em grupo (somatório das respostas DF e D), enquanto $22,22 \%$ se declararam indecisos frente à afirmação.

A ausência de uma maioria de respostas concordantes ou discordantes frente à afirmação $\mathrm{Q} 9$ foi também observada na disciplina Laboratório de Química Geral (Figura 2b): 31,58\% dos alunos explicitaram sua preferência por aulas expositivas dialogadas (somatório das respostas CF e C) e $42,11 \%$ por aulas nas quais predominam atividades em grupo (somatório das respostas DF e D), enquanto $26,32 \%$ se declararam indecisos. Tal resultado não é surpreendente, pois pesquisas indicam que do ponto de vista de muitos alunos ensinar é algo que só os professores podem fazer, sendo mais confortável para eles um estilo de ensino baseado exclusivamente na exposição do professor. ${ }^{13,14} \mathrm{O}$ fato da cooperação entre os pares ainda não estar presente de forma sistemática nos cursos universitários dificulta o desenvolvimento nos alunos do sentimento da importância dessa cooperação.

No que diz respeito à afirmação Q10, enquanto a maioria dos alunos da disciplina Comunicação e Expressão em Linguagem Científica I (62,96\%, somatório das respostas CF e C) indicou que teria gostado mais do jigsaw se tivesse sido ajudado mais diretamente pelo docente/estagiário PAE (Figura 2a), na disciplina Laboratório de Química Geral (Figura 2b) a maioria dos alunos discordou de tal afirmação $(64,42 \%$, somatório das respostas DF e D). Provavelmente, as naturezas distintas das disciplinas, a primeira de cunho teórico e a segunda de cunho prático, tenham contribuído para a obtenção desse resultado. De fato, embora nas disciplinas práticas os alunos estejam habituados a trabalhar de forma mais independente do professor, o mesmo não costuma acontecer nas disciplinas teóricas, fazendo com que os alunos da disciplina Comunicação e Expressão em Linguagem Científica I se surpreendessem com o papel desempenhado pelo professor. Papel esse que na aprendizagem cooperativa ganha novas dimensões: quanto mais bem sucedido for o professor, maior será a transferência de 'poder' para os alunos, assim eles se tornarão mais autônomos, responsáveis e capazes de se auto-organizarem. ${ }^{8}$

\section{Necessidades formativas dos professores de Ciências}

Tendo em vista os resultados provenientes da análise da avaliação da proposta didática, relacionamos e discutimos os mesmos do ponto de vista formativo proposto por Carvalho e Gil-Pérez. ${ }^{9}$ Pautamos a discussão também nas atividades realizadas pelos estagiários nas duas etapas do PAE. Segundo os autores, são necessidades formativas dos professores de Ciências: 
Conhecer o conteúdo da disciplina: tendo sido supervisionados pelos docentes responsáveis pelas disciplinas em questão, os estagiários participaram da elaboração das atividades relacionadas aos conteúdos ministrados em sala de aula. Assim, em diversas ocasiões, esclareceram dúvidas dos alunos. Nessa perspectiva, os estagiários entraram em contato com os conteúdos das disciplinas de forma a dominá-los. Esse domínio provavelmente contribuiu para que a grande maioria dos alunos, em ambas as disciplinas, respondesse positivamente, quanto ao fato de terem adquirido conhecimento substancial sobre os conteúdos estudados (Q8).

Questionar as ideias docentes de "senso comum" sobre a aprendizagem de Ciências: a inserção dos pós-graduandos no ambiente de ensino durante um semestre é curto para que questionamentos dessa natureza sejam elaborados em plenitude. Acreditamos que suprir essa necessidade formativa exigiria um maior tempo de imersão na sala de aula, assim como a participação dos estagiários em discussões direcionadas à realização de reflexões sobre aspectos inerentes à aprendizagem de Ciências.

Adquirir conhecimentos teóricos sobre aprendizagem de $\mathrm{Ci}$ ências: acreditamos que essa necessidade foi contemplada pela preparação pedagógica que ocorreu na disciplina mencionada anteriormente, SQF5798-Aspectos Avançados da Docência no Ensino Superior de Química, na qual os estagiários estudaram diversos princípios e tendências atuais da área de Educação em Química. O fato dos estagiários a partir de conhecimentos teóricos adquiridos na disciplina terem elaborado com sucesso as propostas didáticas aqui relatadas também é um indicativo de que a necessidade formativa em pauta foi contemplada.

Saber analisar criticamente o "ensino tradicional": consideramos essa necessidade formativa de grande complexidade, pois para que seja contemplada exige o rompimento de alguns paradigmas. No entanto, ao propor uma atividade didática que tem entre os seus objetivos o desenvolvimento de habilidades não apenas cognitivas, mas também interpessoais, os estagiários foram movidos, talvez mesmo que de forma intuitiva, a partir da realização de uma análise crítica do "ensino tradicional".

Saber preparar atividades: acreditamos que essa necessidade formativa foi contemplada, uma vez que os estagiários elaboraram e aplicaram a proposta didática aqui relatada. Entretanto, a sua execução, por si só, não garante que essa necessidade formativa tenha sido alcançada pelos estagiários. Em contraponto, essa perspectiva ganha força tendo em vista a satisfação expressa por parte significativa dos alunos, em ambas as disciplinas, ao afirmarem que gostaram de trabalhar no formato de aula jigsaw (Q3 e Q4) e que participariam novamente de aulas nesse formato (Q5).

Saber dirigir os trabalhos dos alunos: o suprimento dessa necessidade formativa foi favorecido pelo fato da condução das aulas no formato jigsaw ter exigido dos estagiários um contato estreito com os grupos de alunos (grupos de base e de especialistas). Seguramente, nesse contexto de aprendizagem a direção dos trabalhos dos alunos costuma ser bem mais efetiva e complexa do que em aulas expositivas. Ademais, a maioria dos alunos, em ambas as disciplinas, discordou da afirmação que diz ser o formato de aula jigsaw confuso e desestruturado (Q7) e concordou sobre o desenvolvimento de trabalho de forma mais independente do que nas aulas expositivas (Q1), indicando também a satisfatória condução das atividades pelos estagiários.

Saber avaliar: a participação do estagiário na avaliação das atividades foi bastante sutil, uma vez que tal tarefa foi realizada majoritariamente pelos professores responsáveis pelas disciplinas. Assim, essa necessidade formativa não foi contemplada de forma efetiva durante o Programa de Aperfeiçoamento de Ensino.

\section{CONSIDERAÇÕES FINAIS}

A participação dos estagiários no Programa de Aperfeiçoamento de Ensino como ação capaz de suprir algumas das necessidades formativas dos futuros professores de ensino superior se mostrou promissora, com base no referencial teórico adotado. De fato, aos estagiários, foi possível o contato com o conteúdo da disciplina com maior profundidade, estando dos dois lados do processo: ensinando e aprendendo simultaneamente. Ademais, as atividades realizadas nas disciplinas permitiram que os mesmos se envolvessem na preparação, condução e avaliação de tarefas didáticas, tornando-os conscientes de que o processo de ensino-aprendizagem começa fora da sala da aula, se estende por toda a atividade e não necessariamente finda em uma avaliação final.

Cabe também destacar o importante papel da etapa de preparação pedagógica, que levou os estagiários a adquirirem conhecimento teórico suficiente para a elaboração e aplicação das propostas de ensino aqui relatadas, acentuando, assim, seu conhecimento sobre o que é ensinar e tornando-os mais preparados para discutirem questões pedagógicas.

Nessa perspectiva, e tendo em vista a aprovação dos graduandos que participaram das propostas, acreditamos que submeter os alunos de pós-graduação a Programas de Aperfeiçoamento de Ensino, como o aqui descrito, seguramente, favorece a sua formação docente. Assim, esperamos que o presente manuscrito contribua para o progresso das discussões sobre os desafios e as possibilidades da formação do professor universitário no nosso país.

\section{REFERÊNCIAS}

1. Pimenta, S. P.; Anastasiou, L. G. C.; Docência no Ensino Superior, $2^{\mathrm{a}}$ ed., Cortez: São Paulo, 2005.

2. Portaria $\mathrm{N}^{\circ}$ 52, 26 de setembro de 2002 da CAPES; Regulamento do Programa de Demanda Social, Brasília, setembro, 2002.

3. Arroio, A.; Rodrigues Filho, U. P.; Silva, A. B. F.; Quim. Nova 2006, 29, 1387.

4. Arroio, A.; Honório, K. M.; Homem-de-Mello, P.; Weber, K. C.; Silva, A. B. F.; Quim. Nova 2008, 31, 1888.

5. Zanon, D. A. V.; Oliveira, J. R. S.; Queiroz, S. L.; Ensaio 2009, 11, 1.

6. http://www.usp.br/prpg/pt/interna1/pae.html, acessada em Junho 2010 e Fevereiro 2011.

7. Johnson, D. W.; Johnson, R. T.; Holubec, E. J.; Los Nuevos Círculos del Aprendizaje: la Cooperación en el Aula y la Escuela, Aique: Virginia, 1999.

8. Cochito, M. I. S.; Cooperação e Aprendizagem: Educação Intercultural, ACIME: Lisboa, 2004.

9. Carvalho, A. M. P.; Gil-Pérez, D.; Formação de Professores de Ciências: Tendências e Inovações, $7^{\mathrm{a}}$ ed., Cortez: São Paulo, 2003.

10. http://www.ppgq.ufscar.br/disc_area_es.php, acessada em Junho 2010 e Fevereiro 2011.

11. http://www.prpg.unicamp.br/bolsas_estagiodocente.phtml, acessada em Junho 2010 e Fevereiro 2011.

12. Eilks, I.; J. Chem. Educ. 2005, 82, 313.

13. Hagen, J. P.; J. Chem. Educ. 2000, 77, 1441.

14. Barbosa, R. M. N.; Jófili, Z. M. S.; Ciência e Educação 2004, 10, 55. 